\title{
AUGMENTED REALITY SEBAGAI MEDIA PENDIDIKAN KESEHATAN UNTUK ANAK USIA SEKOLAH
}

\author{
Yolinda Suciliyana $^{1}$, La Ode Abdul Rahman ${ }^{2}$ \\ ${ }^{1}$ Keperawatan Komunitas, Fakultas Ilmu Keperawatan Universitas Indonesia \\ ${ }^{2}$ Departemen Dasar Keperawatan dan Keperawatan Dasar, Fakultas Ilmu Keperawatan \\ Universitas Indonesia \\ Email : yolinda.suciliyana@gmail.com
}

\begin{abstract}
ABSTRAK
Teknologi di bidang multimedia yang sedang berkembang saat ini adalah Augmented Reality (AR). Pemanfaatan Augmented Reality sebagai media untuk edukasi anak memberikan pandangan baru terhadap media edukasi yang ada saat ini, bukan hanya menggunakan objek secara nyata tapi juga menggunakan objek berbentuk virtual dalam penyampaian informasi. AR merupakan teknologi yang menggabungkan benda maya tiga dimensi ke dalam sebuah lingkungan nyata tiga dimensi dan menampilkannya dalam waktu nyata (real time). Penelitian ini memberikan gambaran dan gagasan dari hasil literatur review tentang perkembangan sistem informasi keperawatan khsusnya pemanfaatan AR sebagai media edukasi untuk anak usia sekolah. Penelitian ini menggunakan literature review, artikel dikumpulkan dengan menggunakan mesin pencari seperti Klinical Key, Science Direct, dan Proquest. Penerapan AR sebagai media pendidikan mampu meningkatkan pengetahuan anak. AR diharapkan mampu mendukung sebagai salah satu media untuk anak usia sekolah sebagai upaya mewujudkan health promotion. Di Indonesia pemanfaatan media AR masih belum banyak di implementasikan apalagi dalam keperawatan. Perlu adanya pengembangan media AR ini dalam dunia keperawatan.
\end{abstract}

Kata kunci : Augmented Reality, Pendidikan kesehatan, Mobile Learning 


\title{
AUGMENTED REALITY AS A HEALTH EDUCATION FOR SCHOOL-AGE
}

\begin{abstract}
Technology in the multimedia field that is currently developing is Augmented Reality (AR). The use of Augmented Reality as a medium for children's education provides a new perspective on the existing educational media, not only using real objects but also using virtual objects in the delivery of information. AR is a technology that discusses three-dimensional virtual objects into a real three-dimensional environment and displays them in real time. This study provide an overview and support of the results of a literature review on the development of nursing information systems specifically the use of $A R$ as an educational for school children. This study uses a literature review, articles collected using search engines such as Clinical Key, Direct Science, and Proquest. The application of AR as an educational medium that is able to increase children's knowledge. AR is expected to be able to support as one of the media for school-age children in an effort to realize health promotion. In Indonesia the use of $A R$ media has not been widely implemented in nursing. Need to develop this AR media in the world of nursing.
\end{abstract}

Keywords : Augmented Reality, Health Education, Mobile Leraning

\section{PENDAHULUAN}

Perkembangan teknologi saat ini secara tidak langsung memberikan dampak kepada masyarakat di Indonesia khususnya dalam perkembangan teknologi informasi dan komunikasi. Teknologi informasi dan komunikasi di era digital saat ini berkembang sangat cepat yang mempengaruhi berbagai media yang sudah ada. Hal tersebut mendorong manusia untuk semakin kreatif dalam mengelola ilmu pengetahuan sehingga mampu merubah pola pikir manusia untuk dapat berfikir secara efektif dan efisien untuk dapat mengimbangi perkembangan di dunia teknologi informasi dan komunikasi di era 4.0 (era digital). Perkembangan teknologi informasi dan komunikasi saat ini banyak melibatkan bidang multimedia karena efektif untuk menyampaikan informasi.

Teknologi multimedia dapat membantu untuk menciptakan lingkungan belajar yang berkualitas tinggi melalui media yang bervariasi seperti teks, grafik, suara, animasi, termasuk Augmented Reality (AR) (Saputri, 2017). Pemanfaatan Teknologi di bidang multimedia yang sedang berkembang saat ini adalah Augmented Reality (Realitas Tertambah) (Hidayat, 2015). AR adalah penggabungan antara benda virtual (maya) dan benda nyata secara alami melalui sebuah proses komputerisasi, sehingga akan terlihat real seperti ada dihadapan pengguna. AR merupakan teknologi yang menggabungkan benda 
maya tiga dimensi (3D) ke dalam sebuah lingkungan nyata tiga dimensi dan menampilkannya dalam waktu nyata (real time) (Kamelia, 2019). AR saat ini telah mengalami perkembangan yang sangat pesat dan telah mempengaruhi berbagai kehidupan salah satunya dalam dunia pendidikan.

Perkembangan dalam bidang pendidikan kesehatan khususnya untuk anak-anak adalah bagaimana cara penyampaian materi kesehatan agar lebih menarik dengan menggunakan sebuah media. Pemilihan media dalam pendidikan kesehatan berpengaruh pada minat siswa terhadap topik yang disampaikan. Salah satu media pendidikan yang dapat digunakan untuk menarik perhatian siswa adalah gambar animasi. Gambar animasi dapat menimbulkan kreatifitas siswa yang beragam dalam membahasakannya. Siswa akan lebih jelas terhadap suatu pokok bahasan atau materi yang disampaikan (Salawati \& Nuke, 2015). Media yang dapat mempermudah penyampaian harus selalu berkembang agar anak-anak tidak bosan. Maka dengan penambahan teknologi AR dapat mengenalkan teknologi tersebut kepada anak-anak sebagai wawasan dalam perkembangan teknologi. Selama ini pendidikan kesehatan hanya menggunakan gambar atau video yang sudah biasa dilihat oleh anak-anak. Media yang digunakan dapat ditemukan di berbagai tempat sehingga mengurangi antusias anak-anak dalam memperhatikan (Hidayat, 2015). Adanya teknologi AR ini dapat menarik perhatian anak-anak karena materi yang di sajikan secara virtual tiga dimensi dan real time sacara interaktif mengenai materi kesehatan, sehingga anak-anak akan lebih paham dan mengerti tentang materi yang ditampilkan. Penggunaan teknologi AR dalam media edukasi dapat lebih menarik perhatian anak- anak dan menjadikan edukasi sebagai hal yang menarik untuk diterapkan.

Penelitian tahun 2017, yang dilakukan di Australia terhadap pasien anak yang menderita Diabetes dilakukan pendidikan kesehatan menggunakan augmented reality game menunjukkan bahwa anak-anak puas dengan permainan dan menganggap bahwa permainan tersebut memberikan manfaat serta mampu menjadi alat edukasi terapeutik yang berharga bagi pasien diabetes pada anak (CalleBustos, Juan, García-García, \& Abad, 2017). Selain itu, penelitian yang dilakukan di New York tahun 2017 menunjukkan bahwa teknologi augmented reality menunjukkan potensi untuk promosi perilaku sehat dan interaksi sosial di antara anak-anak (Das, 2017).

Perkembangan AR sebagai media pendidikan mengalami peningkatan dalam beberapa tahun terakhir. Bacca et al (dalam Calle-Bustos et al., 2017) telah melakukan tinjauan yang mencakup 32 makalah yang diterbitkan dalam jurnal yang terindeks di JCR antara tahun 2003 dan 2013. Salah satu tujuannya adalah untuk mengidentifikasi di bidang pendidikan mana AR sudah diterapkan. Bidang target didasarkan pada Klasifikasi Standar Pendidikan Internasional. Analisisnya menunjukkan bahwa 
sebagian besar studi $(40,6 \%)$ berada di bidang "Sains", contoh dalam bidang ini adalah matematika dan geometri atau belajar tentang siklus air. "Humaniora \& Seni" adalah bidang pendidikan kedua di mana AR paling banyak diterapkan (21,9\%). Contoh dalam bidang ini adalah pembelajaran bahasa atau belajar tentang ilmu numismatik. AR diterapkan dalam "Teknik, Manufaktur dan Konstruksi" (15,6\%). AR diterapkan dalam "Ilmu Sosial, Bisnis dan Hukum" (12,5\%). AR diterapkan di "Layanan dan Lainnya (perjalanan, transportasi, layanan keamanan dan hotel)" (6,3\%) dan dalam "Kesehatan dan Kesejahteraan" (3,1\%). Contoh dalam "Kesehatan dan Kesejahteraan" adalah belajar tentang morfologi gigi.

Berdasarkan hal tersebut dapat diketahui bahwa AR dapat digunakan sebagai media dalam bidang pendidikan kesehatan khsusnya untuk anak-anak usia sekolah. Penulisan artikel ini bertujuan untuk memberikan gambaran dan gagasan dari hasil literatur review tentang perkembangan sistem informasi keperawatan khsusnya pemanfaatan AR sebagai media edukasi untuk anak usia sekolah.

\section{METODE PENELITIAN}

Penelitian ini menggunakan metode literature review dengan menggunakan keyword "augmented reality as a health education for school age children". Fokus penelitian ini adalah perkembangan augmented reality di Indonesia, Augmented reality sebagai media pendidikan kesehatan anak usia sekolah, manfaat augmented reality. Literatur yang digunakan berupa artikel yang dkumpulkan dengan menggunakan mesin pencari seperti Klinical Key, Science Direct, dan Proquest dengan rentang tahun artikel yang digunakan yaitu 10 tahun terakhir. Berikut adalah beberapa artikel yang dianalisa sesuai dengan tema yang dibahas, yaitu pemanfaatan augmented reality: 
Tabel 1. Artikel yang mendukung penulisan Literatur Review

\begin{tabular}{|c|c|c|c|c|c|c|}
\hline No & $\begin{array}{l}\text { Penulis/ } \\
\text { Tahun }\end{array}$ & Judul Penelitian & Nama Jurnal & Tujuan Penelitian & $\begin{array}{l}\text { Metode } \\
\text { Penelitian }\end{array}$ & Hasil Penelitian \\
\hline 1. & $\begin{array}{l}\text { (Saputri, } \\
\text { 2017) }\end{array}$ & $\begin{array}{l}\text { Penggunaan } \\
\text { Augmented } \\
\text { Reality Untuk } \\
\text { Meningkatkan } \\
\text { Penguasaan Kosa } \\
\text { Kata dan Hasil } \\
\text { Belajar Dian }\end{array}$ & $\begin{array}{l}\text { JUTISI Vol. } 6 \\
\text { No.1 }\end{array}$ & $\begin{array}{l}\text { Mengetahui } r \text { pengaruh } \\
\text { augmented reality pada } \\
\text { pendidikan berdasarkan kajian } \\
\text { literatur hasil penelitian di } \\
\text { bidang tersebut dan untuk } \\
\text { mengetahui potensi } \\
\text { pemanfaatan teknologi tersebut } \\
\text { sebagai media pembelajaran } \\
\text { Bahasa Inggris untuk } \\
\text { meningkatkan penguasaan kosa } \\
\text { kata dan hasil belajar siswa. }\end{array}$ & Literatur review & $\begin{array}{l}\text { Pemanfaatan teknologi multimedia } \\
\text { khususnya augmented reality dalam } \\
\text { pembelajaran interaktif telah terbukti dapat } \\
\text { meningkatkan motivasi belajar siswa. }\end{array}$ \\
\hline 2. & $\begin{array}{l}\text { (Hidayat, } \\
\text { 2015) }\end{array}$ & $\begin{array}{l}\text { Penerapan } \\
\text { teknologi } \\
\text { Augmented Reality } \\
\text { sebagai media } \\
\text { edukasi kesehatan } \\
\text { gigi bagi anak }\end{array}$ & $\begin{array}{l}\text { Creative } \\
\text { Information } \\
\text { Technology } \\
\text { Journal }\end{array}$ & $\begin{array}{l}\text { Mengetahui } r \text { pengaruh } \\
\text { augmented reality sebagai } \\
\text { media edukasi kesehatan gigi } \\
\text { bagi anak usia dini }\end{array}$ & Experimental & 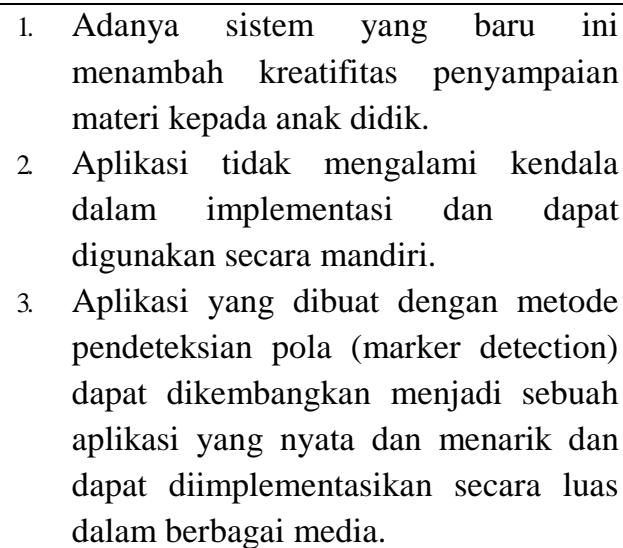 \\
\hline 3. & $\begin{array}{l}\text { (Hsu, Lin, \& } \\
\text { Yang, 2017) }\end{array}$ & $\begin{array}{l}\text { Impact of } \\
\text { augmented reality } \\
\text { lessons on students } \\
\text { STEM interest }\end{array}$ & $\begin{array}{l}\text { Research and } \\
\text { Practice in } \\
\text { Technology } \\
\text { Enhanced }\end{array}$ & $\begin{array}{l}\text { Menyelidiki persepsi siswa } \\
\text { sekolah menengah tentang AR }\end{array}$ & Experimental & $\begin{array}{l}\text { Siswa memiliki persepsi positif tentang } \\
\text { pelajaran AR dan simulator (rata-rata } \\
\text { keseluruhan }=4,1 \text { ) setelah menyelesaikan } \\
\text { dua pelajaran . Studi ini memberikan }\end{array}$ \\
\hline
\end{tabular}




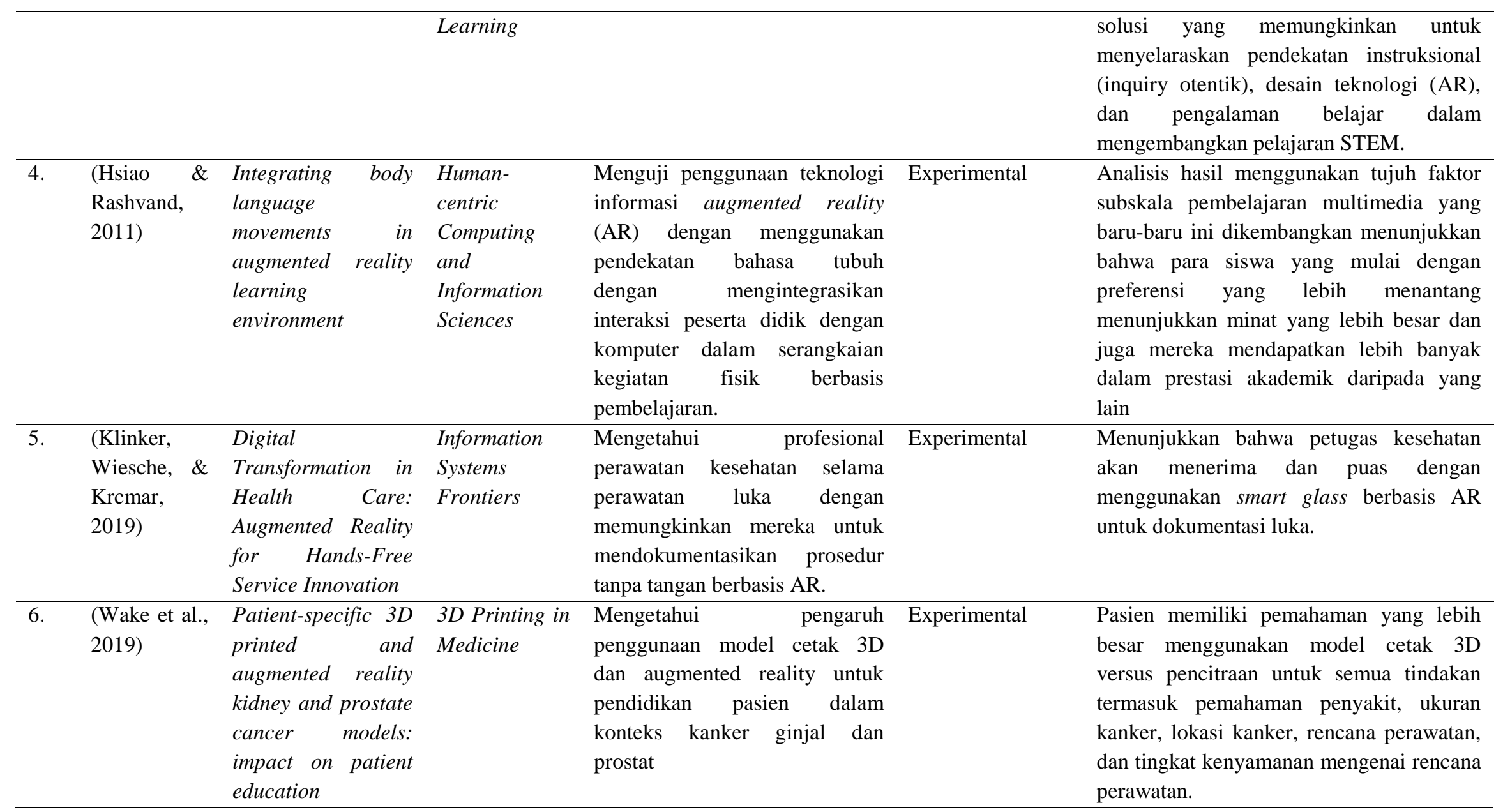




\section{KAJIAN LITERATUR}

Aplikasi pertama dari Augmented Reality dikembangkan oleh Ivan Edward Sunderland pada tahun 1968 dengan sistem teropong "efek kedalaman kinetik" yang terbuat dari dua tabung sinar katoda. Tahun 1991 definisi augmented reality pertama kali dijelaskan oleh Tom Caudell dari Perusahaan Boeing. Sejak saat itu, AR mulai dikenal popularitasnya dan semakin meningkat bahkan telah mencapai tingkat tinggi dalam lustrum terakhir. Aplikasi AR juga lebih mudah karena banyak perangkat yang lebih kompatibel dengan teknologi tersebut (Azuma, 1997 dalam Farronato et al., 2019).

Definisi augmented reality mengacu pada "teknologi yang melapiskan gambar yang dihasilkan komputer pada pandangan pengguna tentang dunia nyata, sehingga memberikan tampilan yang terlihat real". Augmented reality menghasilkan interaksi antara lingkungan nyata dan objek virtual (Farronato et al., 2019). Benda-benda maya menampilkan informasi berupa label maupun objek virtual yang hanya dapat dilihat dengan kamera handphone maupun dengan komputer. Sistem dalam augmented reality bekerja dengan menganalisa secara real time objek yang ditangkap dalam kamera. Benda-benda maya berfungsi menampilkan informasi yang tidak dapat diterima oleh manusia. Hal ini membuat AR berguna sebagai alat untuk membantu persepsi dan interaksi penggunanya dengan dunia nyata. Informasi yang ditampilkan oleh benda maya membantu penggunanya melakukan kegiatan-kegiatan dalam dunia nyata. Tidak seperti virtual reality yang sepenuhnya menggantikan kenyataan, namun AR hanya menambahkan atau melengkapi kenyataan (Saputtra, 2017).
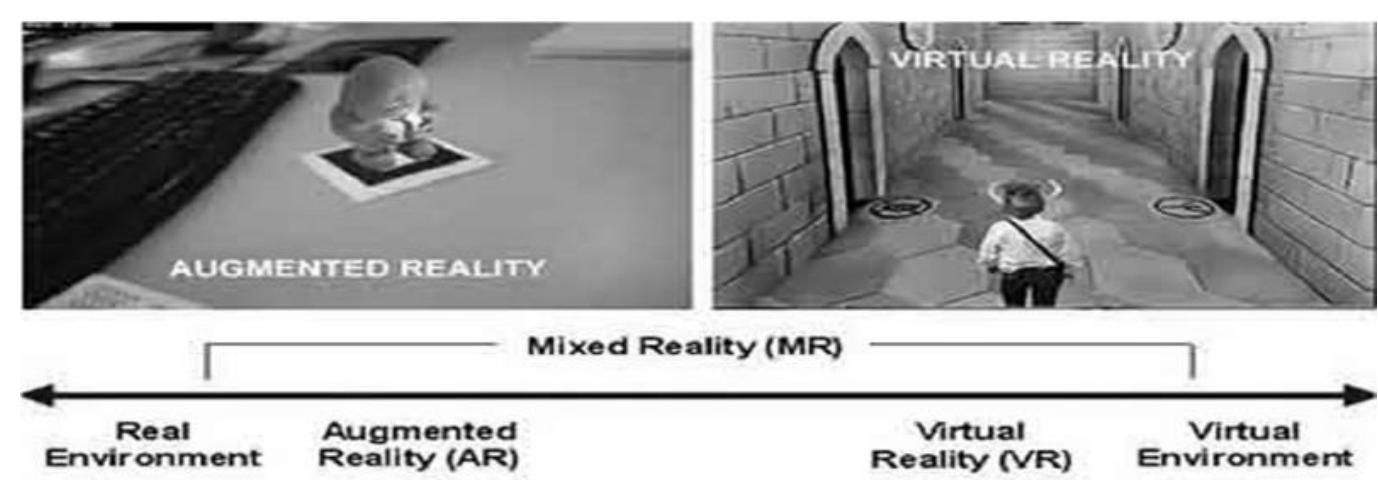

Gambar 1. Perbedaan Augmented Reality dan Virtual Reality

(Kamelia, 2019) 


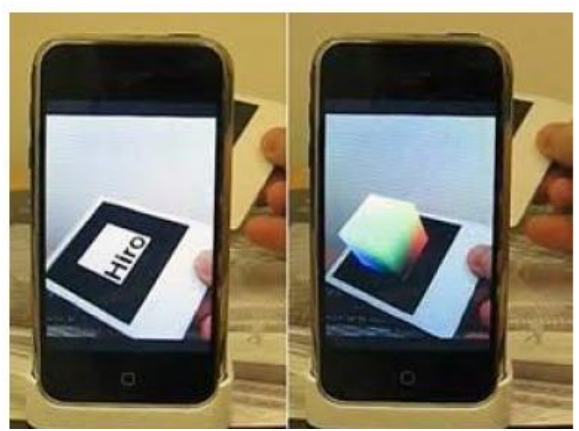

Gambar 2. Contoh Augmented Reality (Kamelia, 2019)

Tujuan dari AR adalah mengambil dunia nyata sebagai dasar dengan menggabungkan beberapa teknologi virtual dan menambahkan data kontekstual agar pemahaman manusia sebagai pengguna menjadi semakin jelas. Data kontekstual ini dapat berupa komentar audio, data lokasi, konteks sejarah, atau dalam bentuk lainnya. Saat ini AR banyak digunakan dalam berbagai bidang seperti kedokteran, militer, manufaktur, hiburan, museum, game pendidikan, pendidikan dan lain-lain (Kamelia, 2019). Oleh karena itu AR diprediksikan mampu menjadi salah satu media digital 3D yang dapat diaplikasikan dalam upaya promosi kesehatan kepada anak sekolah.
Pada prinsipnya ada tiga komponen yang dibutuhkan untuk melakukan pengembangan teknologi AR ini, yaitu: Komputer, Head Mounted Display (HMD), dan Marker. Terdapat dua tipe utama perangkat Head-Mounted Display (HMD) yang digunakan dalam aplikasi AR, yaitu: Opaque Head-Mounted Display dan See-Through Head-Mounted Display. Marker biasanya merupakan ilustrasi hitam dan putih persegi dengan batas hitam tebal dan latar belakang putih. Komputer akan mengenali posisi dan orientasi marker dan menciptakan dunia virtual 3D yaitu titik $(0,0,0)$ dan 3 sumbu yaitu $\mathrm{X}, \mathrm{Y}$,dan $\mathrm{Z}$ (Kamelia, 2019).

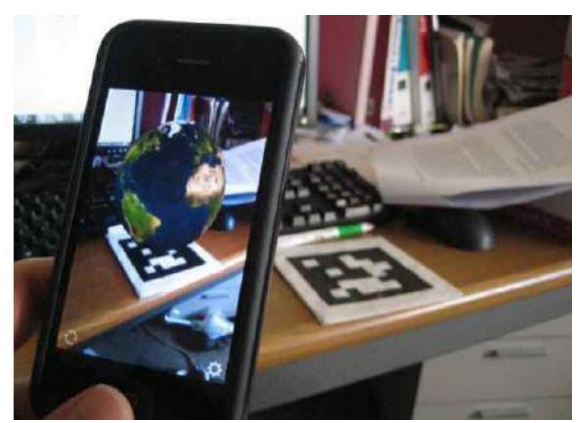

Gambar 3. AR dengan Marker

(Kim, 2011: 1070, 1073)

Aplikasi AR dalam bidang pendidikan digunakan sebagai media pembelajaan interaktif pada mata pelajaran Kimia Dasar terbukti efetif dan mampu membantu siswa dalam memahami molekul-molekul kimia 
(Kamelia, 2019). Berdasarkan penelitian Saputri (2017) Augmented Reality dapat diterapkan sebagai media pembelajaran untuk meningkatkan penguasaan kosa kata bahasa Inggris dan hasil belajar, dengan memperhatikan aspek desain instruksional yang baik.

Salah satu aplikasi teknologi AR adalah dalam bidang kesehatan. Contoh

penggunaannya pada pemeriksaan sebelum operasi, seperti CT Scan atau MRI, yang memberikan gambaran kepada ahli bedah mengenai anatomi internal pasien. Dari gambar-gambar ini kemudian pembedahan mulai direncanakan. Penggunaan lain adalah untuk pencitraan ultrasonik untuk USG ibu hamil (Kamphuis, Barsom, Schijven, \& Christoph, 2014).

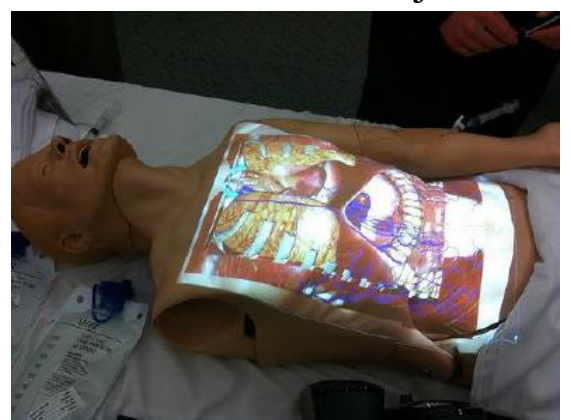

Gambar 4. AR dalam bidang Kesehatan (Hidayat, 2015)

Penggunaan AR untuk pendidikan kesehatan diantaranya yaitu penggunaan Game AR dengan perangkat seluler untuk memperkirakan porsi karbohidrat (pilihan karbohidrat) dari makanan yang berbeda pada penderita diabetes pada anak. Kontribusi utamanya adalah bahwa aplikasi ini dapat menentukan volume makanan yang sebenarnya dan menyimpulkan

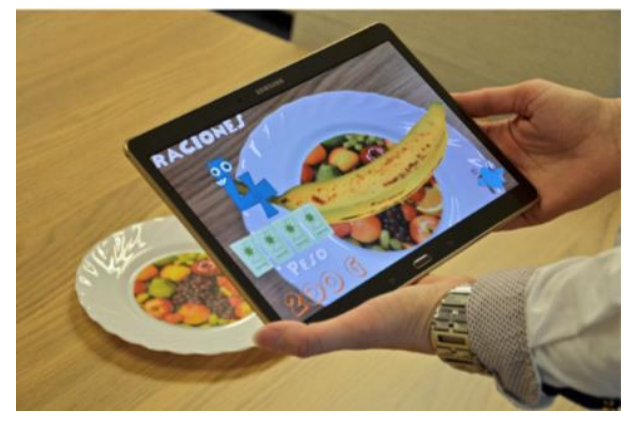

Gambar 5. AR untuk memperkirakan porsi karbohidrat

(Calle-Bustos et al., 2017) beratnya (Calle-Bustos et al., 2017). Selain itu, penerapan Augmented Reality di Indonesia untuk edukasi kesehatan masih sangat terbatas salah satunya contoh sebagai model media edukasi kesehatan gigi pada anak oleh Hidayat (2015) dengan perangkat notebook memberikan hasil bahwa anak-anak lebih tertarik dan antusias dengan pembelajaran yang diberikan.

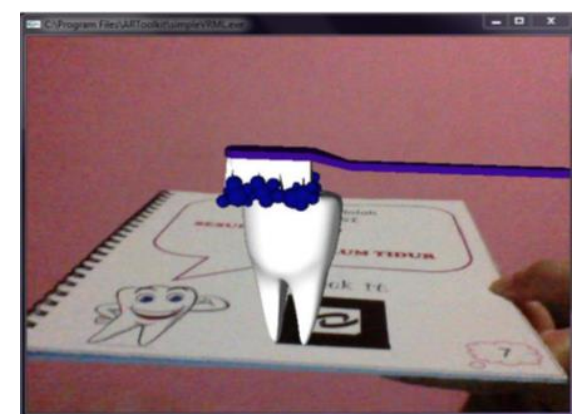

Gambar 6. Edukasi Kesehatan Gigi (Hidayat, 2015) 
Efektifitas Augmented Reality dapat ditingkatkan bila digabungkan dengan teknologi lain seperti perangkat mobile. Pemanfaatan teknologi Augmented Reality dibutuhkan perangkat mobile. Perangkat mobile seperti laptop, personal digital assistant, dan ponsel telah menjadi alat belajar yang sangat potensial baik untuk pembelajaran di ruang kelas maupun di luar ruangan (Sung et al., 2016). Dalam penelitian, mengungkapkan bahwa efek menggunakan perangkat mobile dalam pendidikan adalah lebih baik daripada ketika menggunakan komputer desktop sebagai intervensi. Berdasarkan temuan tersebut, Sung, Chang dan Liu berpendapat bahwa dibutuhkannya elaborasi pembangungan desain intruksional yang memanfaatkan perangkat mobile. Hal tersebut dapat diwujudkan dengan memperhatikan 3 hal berikut: (1) Memanfaatkan efek pedagogis perangkat mobile melalui desain yang rumit dari belajar scenario atau mengajar. (2) Meningkatkan kualitas desain eksperimental untuk intervensi perangkat selular. (3) Memberdayakan praktisi pendidikan melalui orkestrasi dari perangkat mobile, perangkat lunak, dan desain pedagogis (Saputri, 2017).

Sebuah penelitian menyatakan bahwa orang dengan cepat beradaptasi dengan mobile learning. Penggunaan perangkat Pocket PC dalam kegiatan belajar termasuk siswa 7-8 tahun telah dianalisa, hasilnya menunjukkan interaksi yang lancar dan mudah antara siswa dan perangkat lunak yang digunakan (Saputri, 2017). Penelitian di atas menunjukkan bahwa penerapan pembelajaran yang memanfaatkan perangkat mobile pada anak usia sekolah dasar sangat memungkinkan dilakukan.

Menurut Villagomez (2010) cara kerja AR dalam menambahkan objek virtual ke lingkungan nyata adalah sebagai berikut:

1. Perangkat input menangkap video dan mengirimkannya ke prosesor.

2. Perangkat lunak di dalam prosesor mengolah video dan mencari suatu pola.

3. Perangkat lunak menghitung posisi pola untuk mengetahui dimana objek virtual akan diletakkan.

4. Perangkat lunak mengidentifikasi pola dan mencocokkannya dengan informasi yang dimiliki perangkat lunak.

5. Objek virtual akan ditambahkan sesuai dengan hasil pencocokan informasi dan diletakkan pada posisi yang telah dihitung sebelumnya.

6. Objek virtual akan ditampilkan melalui perangkat tampilan

Sedangkan secara teknis, cara kerja Augmented Reality dibagi menjadi 4 tahapan menurut Matthias \& Kuckelhaus (2014) yaitu:

1. Capture

Pada tahapan ini dilakukan pengambilan gambar (Video Capturing) menggunakan media kamera yang diarahkan pada objek yang dijadikan marker.

2. Identification

Pada tahapan ini akan dilakukan 
identifikasi kesesuaian gambar yang ditangkap pada proses capture dengan gambar marker yang telah dikonfigurasikan dengan system.

3. Processing

Pada tahapan ini dilakukan proses pengujian dari hasil proses deteksi marker sebelumnya untuk mengetahui posisi penyimpanan konten virtual yang ada. Posisi dari konten virtual dapat di identifikasi melalui marker atau dengan melakukan pelacakan pada GPS tergantung bagaimana sistem ini di integrasikan.

\section{Visualization}

Pada Tahapan terakhir ini konten virtual akan di tampilkan. Konten ini dapat berupa teks, gambar, video, dan objek 3D.

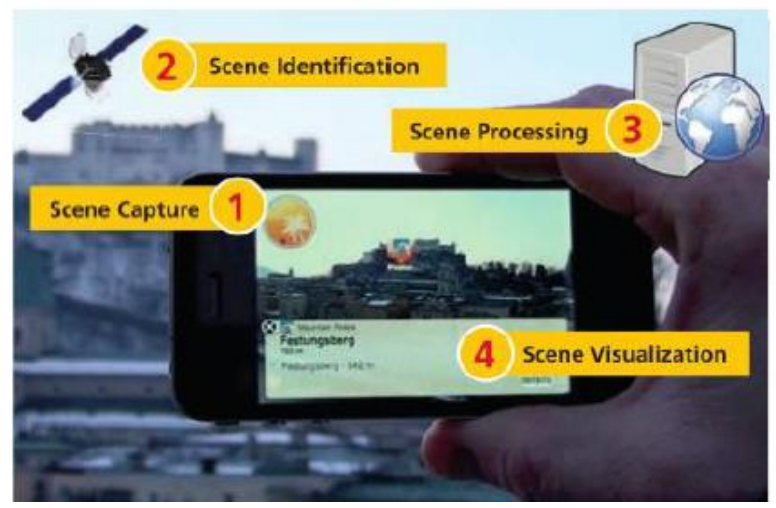

Gambar 7 . Cara Kerja Augmented Reality

(Matthias, \& Kuckelhaus, 2014)

\section{PEMBAHASAN}

\section{Manfaat dan Dampak}

Kajian yang dilakukan oleh Radu et al, menemukan pemanfaatan Augmented Reality dalam pendidikan memberikan dampak yang positif, yaitu menarik untuk pembelajaran, peningkatan aksesibilitas konten pendidikan, meningkatkan kontrol siswa terhadap konten pendidikan, membuka peluang untuk pembelajaran kolaboratif, memotivasi siswa untuk terlibat aktif, dan mengubah suatu yang abstrak menjadi konkrit (Saputri, 2017).

Beberapa bidang yang telah menerapkan Augmented Reality, diantaranya adalah:

1. Bidang Kedokteran, Augmented
Reality digunakan dalam simulasi seperti simulasi operasi yang secara resiko berdampak fatal bagi pasien. Dengan melakukan simulasi diharapkan dapat meminimalisir resiko yang ada karena petugas medis telah mendapatkan gambaran terlebih dahulu mengenai organ tubuh pasien yang akan di operasi.

2. Bidang Militer, bertahun-tahun menggunakan tampilan dalam kokpit yang menampilkan informasi kepada pilot pada kaca pelindung kokpit atau kaca depan helm penerbangan mereka. Ini merupakan sebuah bentuk tampilan augmented reality.

3. Bidang Industri, pemanfaatan Augmented Reality dalam bidang 
industri meliputi pembuatan simulasi mesin yang kompleks, dan sebagai media pemasaran serta promosi.

4. Bidang Pendidikan, pemanfaatan Augmented Reality dalam dunia pendidikan saat ini telah banyak diterapkan, mulai dari sebagai media pendukung untuk menarik perhatian peserta didik, sampai dengan media penjelasan seputar materi yang disampaikan. Pembelajaran berbasis AR dapat menjadi alternatif pendekatan yang dapat digunakan oleh guru untuk meningkatkan minat dan prestasi belajar siswa (Saputri, 2017).

Pemanfaatan teknologi

multimedia khususnya augmented reality dalam pembelajaran interaktif telah terbukti dapat meningkatkan motivasi belajar siswa. Namun augmented reality belum banyak dimanfaatkan di bidang pendidikan dan lebih sedikit lagi yang menggunakannya pada pendidikan anak usia sekolah. Pembelajaran berbasis Augmented Reality (Augmented Reality based Learning) adalah rangkaian kegiatan terstruktur dimana terjadi interaksi antara siswa, guru dan bahan belajar dengan memanfaatkan teknologi Augmented Reality pada suatu lingkungan belajar yang kondusif sehingga hasil belajar yang memenuhi tujuan pembelajaran dapat dicapai. Pembelajaran berbasis Augmented Reality dirancang dengan memperhatikan tujuan pembelajaran, perkembangan kognitif dan karakteristik siswa sehingga tercipta pembelajaran yang interaktif dan menarik yang dapat membantu siswa memahami tentang materi yang disampaikan (Saputri, 2017).

\section{Hambatan Penggunaan Augmented Reality}

Walaupun demikian, mengadopsi Augmented Reality dalam pendidikan kesehatan menghadapi beberapa tantangan, seperti masalah integrasi dengan metode belajar tradisional, biaya untuk pengembangan dan pemeliharaan sistem Augmented Reality, dan ketahanan terhadap teknologi baru (Saputri, 2017).

\section{Penerapan Augmented Reality di Indonesia}

Perkembangan teknologi informasi dan komunikasi, berdampak pada profesi perawat yang diberikan kemudahan dalam proses intervensi. Pada dasarnya konsep keperawatan mengacu pada perawatan berkelanjutan (continuum of care). Pemanfaatan teknologi diterapkan sebagai upaya promotif dan preventif. Salah satu media yang dapat digunakan sebagai pendidikan kesehatan yaitu augmented reality. Teknologi tersebut sudah dikembangkan sebagai media pendidikan (Saputtra, 2017). Namun, di Indonesia belum banyak penelitian yang menjelaskan bahwa aplikasi augmented reality digunakan oleh perawat dalam pendidikan kesehatan.

Beberapa hasil penelitian dan fenomena yang terjadi bahwa perkembangan augmented reality di Indonesia masih berfokus pada dunia pendidikan secara umum (Nurcahyo \& Hantono, 2015). Pemanfaatan AR belum 
spesifik terhadap penggunaan sebagai media untuk pendidikan kesehatan yang digunakan oleh perawat.

Augmented reality dalam layanan promotif diharapkan mampu menjadi salah satu media pendidikan kesehatan khususnya untuk anak usia sekolah. Penerapan augmented reality dianjurkan sebagai upaya peningkatan paradigma sehat di Indonesia.

\section{SIMPULAN}

Peningkatan berbagai macam media informasi kesehatan baik secara manual maupun digital untuk masyarakat menjadi salah satu target pemerintah Indonesia. Augmented Reality dapat menjadi salah satu solusi dalam upaya menyediakan media informasi kesehatan khususnya untuk anak-anak (Saputtra, 2017).

Perawat memiliki peran dalam upaya peningkatan informasi kesehatan di Indonesia. Perawat dapat memanfaatkan perkembangan teknologi dalam pendidikan kesehatan dengan menerapkan augmented reality. Penerapan media tersebut dilakukan dengan memberikan asuhan keperawatan berupa tindakan promotif.

\section{UCAPAN TERIMAKASIH}

Pada kesempatan ini, penulis ingin mengucapkan terimakasih kepada berbagai pihak yang telah membantu terwujudnya literatur review ini:
1. Fakultas Ilmu Keperawatan Universitas Indonesia
2. Jurnal Surya Muda

\section{DAFTAR PUSTAKA}

Calle-Bustos, A. M., Juan, M. C., García-García, I., \& Abad, F. (2017). An Augmented Reality Game to Support Therapeutic Education for Children with Diabetes. PLoS ONE, 12(9), 124.

https://doi.org/10.1371/journal.p on e.0184645

Das, P. et al. (2017). Augmented Reality Video Games: New Possibilities and Implications for Children and Adolescents. Multimodal Technologies and Interaction, 1(4),

8.

https://doi.org/10.3390/mti10200 08

Farronato, M., Maspero, C., Lanteri, V., Fama, A., Ferrati, F., Pettenuzzo, A., \& Farronato, D. (2019). Current State of the Art in the Use of Augmented Reality in Dentistry: A Systematic Review of the Literature. BMC Oral Health, 19(1). https://doi.org/10.1186/s12903019-0808-3

Hidayat, T. (2015). Penerapan Teknologi Augmented Reality sebagai Media Edukasi Kesehatan Gigi bagi Anak. Creative Information Technology Journal, 2(1), 77-92. Retrieved from http://citec.amikom.ac.id/main/in d ex.php/citec/article/view/39\%5Cn $\mathrm{h}$

ttp://citec.amikom.ac.id/main/ind 
e x.php/citec/article/view/39/39.

Hsiao, K. F., \& Rashvand, H. F. (2011). Integrating Body Language Movements in Augmented Reality Learning Environment. Human-Centric Computing and Information Sciences, 1(1), 1-10. https://doi.org/10.1186/21921962-1-1

Hsu, Y. S., Lin, Y. H., \& Yang, B. (2017). Impact of Augmented Reality Lessons on Students STEM Interest. Research and Practice in Technology Enhanced Learning, 12(1). https://doi.org/10.1186/s41039016-0039-z.

Kamelia, L. (2019). Perkembangan Teknologi Augmented Reality sebagai Media Pembelajaran Interaktif pada Mata Kuliah Kimia Dasar. Noviember 2018, IX(1), 1. Retrieved from https://www.gob.mx/semar/quehacemos.

Klinker, K., Wiesche, M., \& Krcmar, H. (2019). Digital Transformation in Health Care: Augmented Reality for Hands-Free Service Innovation. Information Systems Frontiers.

https://doi.org/10.1007/s10796019-09937-7

Kamphuis, C., Barsom, E., Schijven, M., \& Christoph, N. (2014). Augmented Reality in Medical Education? Perspectives on Medical
Education, 3(4), 300-311. https://doi.org/10.1007/s40037013-0107-7.

Kim, J., Jun, H. (2011). Implementation of image processing and augmented reality programs for smart mobile device. Strategic Technology (IFOST), 2011 6th International Forum 1(2) pp.1070, 1073.

Matthias, H \& Kuckelhaus, M. (2014). Augmented Reality In Logistics Changing The Way We See Logistics - A DHL Perspective 2014. DHL Customer Solutions \& Innovation

Nurcahyo, D. E., \& Hantono, B. S. (2015). Pemanfaatan Augmented Reality dalam Dunia Pendidikan untuk Mempelajari Anatomi Tubuh Manusia Berbasis Android. Jurnal, 2015(Sentika), 193-198.

Salawati, T. \& Nuke, D. I. (2015). Tahap analisis untuk pengembangan "ASETARO" komik pendidikan kesehatan untuk anak tentang bahaya merokok. The $2^{\text {nd }}$ University Research Coloquium. ISSN 24079189. Semarang: Universitas Muhammadiyah Semarang.

Saputri, D. S. C. (2017). Penggunaan Augmented Reality untuk Meningkatkan Penguasaan Kosa Kata dan Hasil Belajar. JUTISI Vol. 6 No.1 , April 2017, 6, 1357-1366. 
Saputtra, F. (2017). Perancangan Media Edukasi Kesehatan Gigi dan Mulut dengan Penerapan Teknologi Augmented Reality pad Sistem Berbasis Android.

Sung, Yao-Ting, Chang, Kuo-En, Liu, Tzu-Chien. (2016). The Effects of Integrating Mobile Devices with Teaching and Learning on Students Learning Performance: A Metaanalysis and Research Synthesis. Journal of Computers \& Education 94 page 252e275

Villagomez. (2010). Augmented Reality. University of Kansas.

Wahyudi, A. K. (2013). Arca :
Perancangan Buku Interaktif Berbasis Augmented Reality pada Pengenalan dan Pembelajaran Candi Prambanan dengan Smartphone Berbasis Android.

Wake, N., Rosenkrantz, A. B., Huang, R., Park, K. U., Wysock, J. S., Taneja, S. S., Chandarana, H. (2019). Patient Specific 3D Printed and Augmented Reality Kidney and Prostate Cancer Models: Impact on Patient Education. $3 D$ Printing in Medicine, 5(1). https://doi.org/10.1186/s41205019-0041-3 